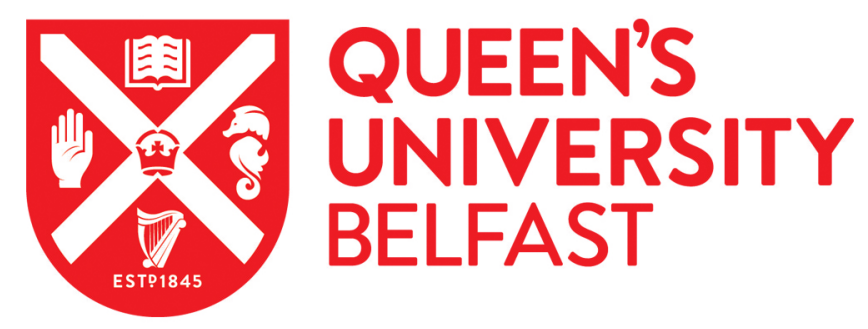

\title{
Novel Hydrogel-Forming Microneedle Array for Intradermal Vaccination in Mice Using Ovalbumin as a Model Protein Antigen
}

Courtenay, A. J., Rodgers, A. M., McCrudden, M. T. C., McCarthy, H. O., \& Donnelly, R. F. (2019). Novel Hydrogel-Forming Microneedle Array for Intradermal Vaccination in Mice Using Ovalbumin as a Model Protein Antigen. Molecular Pharmaceutics, 16(1), 118-127. https://doi.org/10.1021/acs.molpharmaceut.8b00895

Published in:

Molecular Pharmaceutics

Document Version:

Peer reviewed version

Queen's University Belfast - Research Portal:

Link to publication record in Queen's University Belfast Research Portal

Publisher rights

Copyright @ 2018 American Chemical Society.This work is made available online in accordance with the publisher's policies. Please refer to any applicable terms of use of the publisher.

\section{General rights}

Copyright for the publications made accessible via the Queen's University Belfast Research Portal is retained by the author(s) and / or other copyright owners and it is a condition of accessing these publications that users recognise and abide by the legal requirements associated with these rights.

Take down policy

The Research Portal is Queen's institutional repository that provides access to Queen's research output. Every effort has been made to ensure that content in the Research Portal does not infringe any person's rights, or applicable UK laws. If you discover content in the Research Portal that you believe breaches copyright or violates any law, please contact openaccess@qub.ac.uk. 


\title{
A novel hydrogel-forming microneedle array for intradermal vaccination in mice using ovalbumin as a model protein antigen
}

\author{
Aaron J Courtenay, Aoife M Rodgers, Maelíosa T.C McCrudden, Helen O. \\ McCarthy, and Ryan F Donnelly*.
}

School of Pharmacy, Medical Biology Centre, Queens University Belfast, 97 Lisburn Road, Belfast BT9 7BL, United Kingdom.

*Corresponding author

Chair in Pharmaceutical Technology,

School of Pharmacy,

Queens University Belfast,

Medical Biology Centre,

97 Lisburn Road,

Belfast,

BT9 7BL,

United Kingdom.

Tel.: +442890972 251

E-mail address: r.donnelly@qub.ac.uk 


\begin{abstract}
Global vaccination strategies have traditionally relied on the hypodermic needle and syringe model. However, to facilitate increased immunisation coverage and reduce costs, novel methods of vaccine delivery are warranted. Dissolving microneedle arrays (MN) have been proposed as an alternative approach to the hypodermic needle, offering the prospect for selfvaccination and increased immunogenicity via direct targeting of skin dendritic cells. This study, for the first time, compares the use of novel hydrogel-forming MNs and dissolving MNs for the delivery of a model protein antigen ovalbumin (OVA). We provide comparative data on both MN types in terms of in vitro characteristics and in vivo immunogenicity. Herein, both MN platforms were tested and characterised in terms of mechanical integrity and insertion properties using a validated skin insertion model. A comparative in vivo vaccination study in $\mathrm{balb} / \mathrm{c}$ mice was conducted, whereby anti-OVA specific IgG was used as a measure of delivery efficacy and subsequent immune response. While vaccination of mice with both MN platforms resulted in IgG responses, those vaccinated with dissolving MNs had significantly higher IgG titres $(p<0.0149)$, despite the quantity of OVA delivered being significantly less. This study highlights the importance of MN design and the potential impact of dissolving MN polymers on the immune response to vaccine antigens. Further, detailed studies, are therefore required to elucidate the effects of polymer-vaccine interactions and their subsequent effect on immune responses.
\end{abstract}

Keywords Microneedle, intradermal vaccination, balb/c, polymer, ovalbumin, IgG, dissolving, hydrogel-forming. 

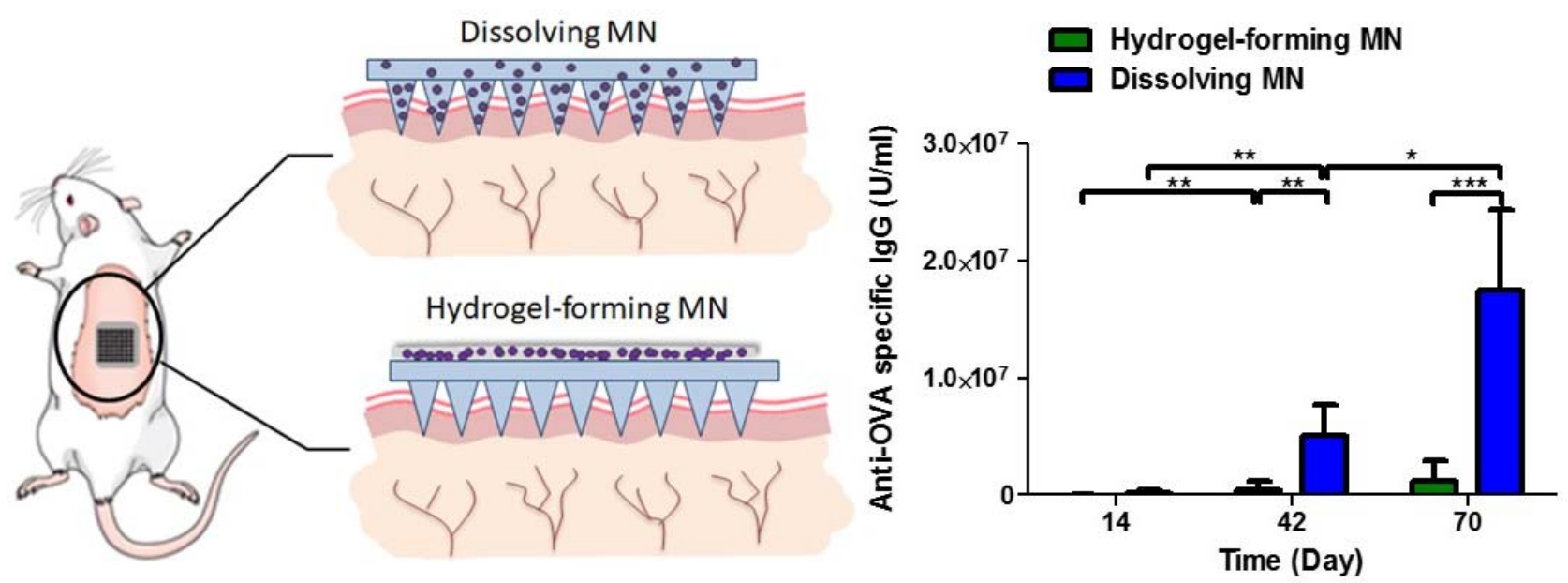

Graphical abstract 


\section{Introduction}

The World Health Organization (WHO) states that vaccination is the single most effective health intervention ever developed. Child immunisation coverage has improved steadily over the past few years and yet, is still heavily reliant on the hypodermic needle and syringe model. An estimated 194 million infants do not receive basic vaccination [1]. Moreover, needle-stick injuries are a recurring problem, specifically within developing countries. Of the 35 million health care workers globally, approximately 2 million experience percutaneous exposure to infectious diseases each year [1]. As such, novel vaccine delivery technologies are necessitated in order to increase vaccination population coverage and reduce costs.

Microneedle (MN) arrays are micron-scale needle-like structures fabricated using a variety of methods, onto a supporting platform. Upon insertion into the skin, the MNs pierce the stratum corneum (SC), penetrating to the deeper skin layers. Different MN array types have been described in the literature, however dissolving MNs have received particular attention for vaccination purposes [2]. Dissolving MNs offer numerous advantages over the conventional hypodermic needle, including targeting of skin antigen presenting cells and subsequent enhanced immune responses [3]. Furthermore, MNs offer the prospect for self-application by patients, reducing the requirement for trained health care professionals and potentially reduced costs. Extensive vaccination programs in pandemic outbreaks may also benefit from the increased coverage that could be achieved by utilising minimally invasive $\mathrm{MN}$ technology [4]. While dissolving MNs have demonstrated their potential for vaccination purposes, they result in polymer deposition in the skin, the effects of which have yet to be investigated.

Hydrogel-forming MN are solid systems, that, when applied to the skin, swell upon uptake of interstitial skin fluid. Vaccine contained within an accompanying reservoir can subsequently permeate through the hydrogel structure and be delivered into the viable skin [5]. Unlike dissolving MNs, hydrogel-forming MNs can be removed intact from the skin following the vaccine dose delivery and thus, avoiding the deposition of polymer within the skin. Furthermore, the cross-link density of the MNs can be tailored to facilitate the rate and degree of swelling of the hydrogel-forming MNs. These systems are therefore "tailorable" and can be changed to suit the dosing schedule of particular vaccines, therefore expanding the potential impact this technology could have. As hydrogel-forming MN arrays contain no vaccine agents, which is instead contained within a reservoir, a simplified fabrication process may be achievable compared to dissolving MN arrays. Mass production of hydrogel-forming $\mathrm{MN}$ 
arrays and reservoirs may prove more cost effective which would have implications for industrial scale up and manufacturing.

To date there have been no published studies investigating the use of hydrogel forming MNs for vaccination purposes. Accordingly, this study tested the feasibility of utilising this approach for delivery of a model protein antigen ovalbumin (OVA). We have previously reported the successful use of dissolving MNs for vaccination purposes and as such, this system was used as a comparative control. Herein, we describe the formulation, characterisation and in vitro evaluation of a novel hydrogel-forming $\mathrm{MN}$ array and provide key insights into the comparative potential of dissolving and hydrogel-forming $\mathrm{MN}$ vaccination platforms. Furthermore, in vivo vaccination studies were conducted to test the immunogenicity of the resultant MNs laden with OVA. Specifically, OVA vaccination using dissolving MN arrays fabricated from aqueous blends of Gantrez ${ }^{\circledR}$ S-97 were compared with a combined system of hydrogel-forming MN arrays used in conjunction with OVA containing lyophilised reservoirs. We report the successful generation of OVA specific IgG using both delivery platforms. To the best of our knowledge, this is the first study demonstrating the potential of hydrogel forming MNs for vaccination purposes 


\section{Materials and Methods}

\subsection{Chemicals}

Ovalbumin $>98 \%$ was purchased from Sigma Aldrich, Dorset, UK. Cryogel Gelatine grade SG3 was obtained from PB Gelatins, Pontypridd, UK and mannitol (Pearlitol ${ }^{\circledR} 50 \mathrm{C}$ ) obtained from Roquette, Lestrem, France. Sucrose and sodium chloride was purchased from Sigma Aldrich, Steinheim, Germany. Poly(methylvinylether-co-maleic acid) (Gantrez ${ }^{\circledR}$ S-97) was gifted to the authors from Ashland Pharmaceuticals, Kidderminster, UK. Ketamine hydrochloride (10 mg/ml) solution for injection was obtained from Pfizer Ltd., Ramsgate Road, Kent, United Kingdom. Xylazine $(100 \mathrm{mg} / \mathrm{ml})$ solution for injection was obtained from Bayer Healthcare LLC, Bergkamen, Germany. BALB/c mice were sourced from Charles Rivers Laboratories Inc., Scotland, UK. Mouse anti-OVA specific IgG Enzyme linked immunosorbent assay (ELISA) KIT was purchased from Alpha Diagnostic, San Antonio, Texas, USA. Isoflurane was sourced from AbbVie Ltd, Maidenhead, UK. 3M ${ }^{\mathrm{TM}}$ Medical-grade poly(ethylene) foam boarder adhesive 4135 was purchased from 3M Science, Minneapolis, USA. Scotchpak ${ }^{\circledR} 2.84 \mathrm{~mm}$ Al vapour coated film was purchased from $3 \mathrm{M}$ Science, Minneapolis, USA. PBS was purchased from Sigma Aldrich, Dorset, UK. All other materials used were of reagent or analytical grade.

\subsection{Preparation of hydrogel-forming MN arrays}

Hydrogel-forming MN arrays were produced from aqueous-polymeric mixtures of $20 \% \mathrm{w} / \mathrm{w}$ poly(methylvinylether co-maleic acid) $\left(\right.$ Gantrez $^{\circledR}$ S-97), 7.5\% w/w poly(ethylene glocol) (PEG), molecular weight 10,000 Da, and 3\% w/w of sodium carbonate. Briefly, Gantrez ${ }^{\circledR}$ S97 and PEG 10,000 were dissolved in water, mixed with $\mathrm{Na}_{2} \mathrm{CO}_{3}$ and centrifuged for 15 min at $3500 \mathrm{rpm}$. Aliquots $(100 \mu \mathrm{l})$ of the formulation were dispensed onto pre-fabricated silicone micro-molds. The silicone micro-molds had previously been laser drilled to give a female template of MN arrays ( 19 x $19 \mathrm{MN}$ over $\left.0.5 \mathrm{~cm}^{2}\right)$. The micro-mould templates consisted of holes of $600 \mu \mathrm{m}$ depth, $300 \mu \mathrm{m}$ open diameter and interspaced by $50 \mu \mathrm{m}$. Following aliquote dispensing the filled molds were held within a steel pressure chamber filled with atmospheric air to $60 \mathrm{PSI}$ and maintained for $15 \mathrm{~min}$, facilitating needle tip filling. MN arrays were dried at $20^{\circ} \mathrm{C}$ for $48 \mathrm{~h}$. $\mathrm{MN}$ arrays were crosslinked by heat $\left(80^{\circ} \mathrm{C}\right)$ for a further $24 \mathrm{~h}$, allowed to cool to room temperature and, subsequently, de-molded $[5,6,7]$.

\subsection{Preparation of ovalbumin-containing lyophilised reservoirs}

Lyophilised drug reservoirs containing OVA were prepared using a process previously 
described by our group [6]. In short, a solution of OVA in distilled water $(0.5 \% \mathrm{w} / \mathrm{w})$ was combined with Cryogel $(10 \% \mathrm{w} / \mathrm{w})$, Pearlitol $(40 \% \mathrm{w} / \mathrm{w})$ sodium chloride $(1 \% \mathrm{w} / \mathrm{w})$ and sucrose $(1 \% \mathrm{w} / \mathrm{w})$. The lyophilisate was mixed in a speed-mixer using a rotation speed of 3000 rpm for $60 \mathrm{~s}$. Following this, the lyophilisate was sonicated at $37^{\circ} \mathrm{C}$ for $60 \mathrm{~min}$. This lyophilisate was aliquoted $(250 \mathrm{mg})$ into cylindrical molds (diameter $10 \mathrm{~mm} \&$ depth $5 \mathrm{~mm}$ ) and frozen to $-80^{\circ} \mathrm{C}$ for a minimum of $60 \mathrm{~min}$. Lyophilisation parameters were $-40^{\circ} \mathrm{C}$ for 48 $\mathrm{h}$ (primary drying) ramped to $20^{\circ} \mathrm{C}$ for $10 \mathrm{~h}$ (secondary drying) with a continuous vacuum pressure of $50 \mathrm{mTorr}$.

\subsection{Preparation of ovalbumin-containing dissolving microneedle arrays}

Dissolving MN arrays containing Gantrez ${ }^{\circledR}$ S-97 and OVA were formulated. Initially, a stock solution was prepared by slowly adding Gantrez ${ }^{\circledR}$ S-97 powder to distilled water in a glass beaker and stirring continuously to form a $40 \% \mathrm{w} / \mathrm{w}$ gel. The stock was then sealed in the glass beaker using Parafilm $\mathrm{M}^{\circledR}$ and refrigerated at $4^{\circ} \mathrm{C}$ for at least $12 \mathrm{~h}$ to allow polymer chain hydration. An equal quantify/amount of OVA solution was added to $40 \% \mathrm{w} / \mathrm{w}$ Gantrez ${ }^{\circledR}$ and these were mixed using a glass rod to achieve a final mixture of Gantrez ${ }^{\circledR}$ S-97 and OVA, 20\% $\mathrm{w} / \mathrm{w}$ and $1.25 \% \mathrm{w} / \mathrm{w}$, respectively. The formulation was centrifuged (15 mins at $3500 \mathrm{rpm}$ ) and aliquoted to pre-fabricated silicone micro-molds with the geometry described in figure 1. Dissolving MN arrays were dried at $20^{\circ} \mathrm{C}$ for $48 \mathrm{~h}$ and de-molded.

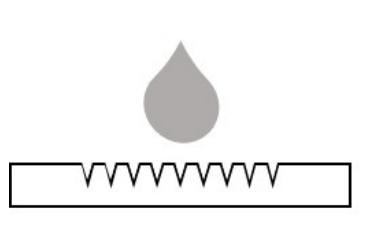

A. Dispense formulation

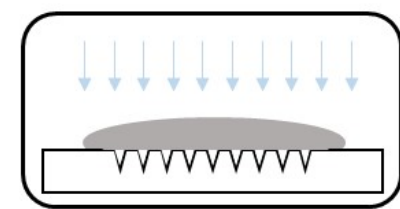

B. Positive pressure environment

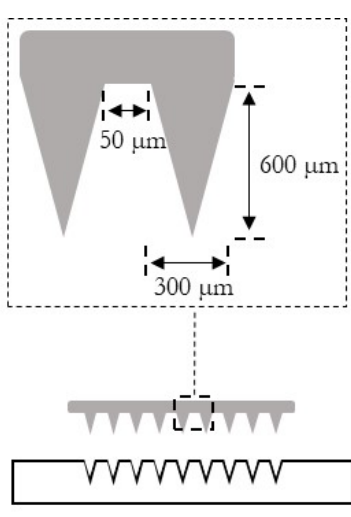

D. MN array removal

Figure 1. A schematic representation of the steps involved in the micro-moulding production of hydrogel-forming and dissolving MNs. 


\subsection{OVA-specific ELISA}

To analyse OVA from in vitro permeation studies, an OVA-specific ELISA was developed. Briefly, mouse monoclonal anti-OVA $(2.5 \mu \mathrm{g} / \mathrm{ml})$ in $0.1 \mathrm{M}$ bicarbonate buffer (pH 9.6) was prepared. Aliquots of $50 \mu \mathrm{l}$ of the diluted anti-OVA antibody were incubated overnight at $4{ }^{\circ} \mathrm{C}$ and washed 5 times with washing buffer (Tween-20 0.05\% (v/v) in PBS (PBST)). The plate was blocked with SuperBlock ${ }^{\circledR}$ T20 (150 $\mu \mathrm{l} /$ well) and incubated for $2 \mathrm{~h}$ at room temperature. After washing with PBST, $50 \mu$ l aliquots of OVA solution (range: $1000 \mathrm{ng} / \mathrm{ml}$ to $100 \mathrm{ng} / \mathrm{ml}$ ) were dispensed in triplicate, incubated for $1 \mathrm{~h}$ at room temperature and washed with PBST. Rabbit anti-OVA polyclonal-biotin conjugate $\left(1 \mu \mathrm{g} / \mathrm{ml}\right.$ in SuperBlock $\left.{ }^{\circledR} \mathrm{T} 20\right)$ was incubated for $1 \mathrm{~h}$ at ambient conditions. Streptavidin-horseradish peroxidase (strep-HRP) conjugate was then incubated for $30 \mathrm{~min}$ and the plate washed using PBST. The substrate, 3,3',5,5'tetramethylbenzidine substrate (TMB), was added and incubated for approximately $15 \mathrm{~min}$. Hydrochloric acid was used to terminate the enzymatic reaction and optical density (450 nm) data recorded using a 96-well plate spectrophotometer, (FluoStar, BMG labtech, London).

\subsection{Dissolution of lyophilised reservoirs and dissolving microneedle arrays}

Time taken to achieve complete dissolution of the dissolving MN arrays, lyophilised reservoirs and dissolving $\mathrm{MN}$ arrays was determined by placing the $\mathrm{MN}$ array or reservoirs into a volumetric flask with $20 \mathrm{ml}$ with solution of PBS (pH 7.4). Samples were continuously stirred at $200 \mathrm{rpm}$ and the time taken to achieve full dissolution was recorded.

\subsection{MN mechanical characterisation and insertion studies}

Our group has previously described how Parafilm $\mathrm{M}^{\circledR}$ can be used to model the $\mathrm{MN}$ insertion depths upon application using manual insertion forces [8]. Briefly, eight Parafilm $\mathrm{M}^{\circledR}$ layers were arranged one on-top the other, measuring approximately $1 \mathrm{~mm}$ in depth. These layers were place onto a sheet of dental wax for mechanical support. Manual insertion studies, using "thumb pressure", equating to approximately $20 \mathrm{~N}$ per array, was applied to each array prototype. MN penetration was assessed visually by counting the holes created on each layer, using a light microscope.

\subsection{In vitro OVA permeation studies on modified Franz cell apparatus}

OVA permeation studies were carried out using Franz cell apparatus, using neonatal porcine skin (excised from stillborn piglets) as the test membrane. Franz diffusion cells (model type: 
FDC-400) with flat flanges and lumen diameter of $15 \mathrm{~mm}$ were housed within a diffusion drive console (FDCD) that supported magnetic stirring $(600 \mathrm{rpm})$ and temperature regulation $(37 \pm$ $1^{\circ} \mathrm{C}$ ) [9]. Neonatal porcine skin was removed from the carcase using a dermatome set to 350 $\mu \mathrm{m}$. The skin was stored at $-20^{\circ} \mathrm{C}$ for no longer than 1 month prior to use. Skin was shaved of hair, thawed in PBS ( $\mathrm{pH}$ 7.4) and allowed to equilibrate to room Franz cell temperature before initiation of the experiment. Skin pieces were placed onto donor compartments using cyanoacrylate adhesive. MN were inserted into skin using manual pressure for $30 \mathrm{~s}$, supported by a sheet of dental wax. Lyophilised reservoirs were placed onto a $10 \mu 1$ aliquot of water on the upper surface of the MN array. A metal weight (13 g) was balanced on the lyophilised reservoir to ensure the MN arrays remained inserted over the course of the $24 \mathrm{~h}$ experimental test period. Steel clamps secured the set-up and Parafilm $\mathrm{M}^{\circledR}$ was used to reduce water loss though evaporation. Regular samples were taken throughout the experimental time and replaced with PBS ( $\mathrm{pH}$ 7.4) pre-heated to $32^{\circ} \mathrm{C}$ to maintain sink conditions. Similarly, OVA permeation from dissolving MN was conducted on the Franz cell apparatus.

\subsection{In vivo OVA vaccination studies in Balb/c mice}

Approval for animal experiments was obtained from the Committee of the Biological Services Unit, Queen's University Belfast. All in vivo experiments were conducted according to the policy of the federation of European Laboratory Animal Science Associations and the European Convention for the protection of vertebrate animals used for experimental and other scientific purposes, with implementation of the principles of the 3R's: Reduction, Replacement, \& Refinement.

Dissolving and hydrogel-forming MN arrays were applied to the dorsal skin of mice. Female $\mathrm{Balb} / \mathrm{c}$ mice ( 8 weeks) were on average $21.2 \pm 2.1 \mathrm{~g}$ upon commencement of the experiment. Hair was removed from the application sites on the mice $24 \mathrm{~h}$ before MN application. Electric clippers were used to remove the hair and, following this, depilatory cream (Gentle depilatory Cream, Nair ${ }^{\mathrm{TM}}$ Co., London, UK) was applied to the same area for 5 mins to remove any remaining hair. The cream was then removed using absorbent paper. A $24 \mathrm{~h}$ skin recovery period was observed to ensure full restoration of the skin barrier function $[5,6]$.

To facilitate MN application, the mice were first anesthetised by intraperitoneal (IP) injection of the sedative agent's ketamine/xylaxine at 100/10 mg/kg. Two MN arrays were applied to the dorsal skin. The MN arrays were held in place by an adhesive foam boarder, with a $10 \mu 1$ 
aliquot of water on the MN array. An OVA-containing lyophilised reservoir was then placed onto the MN array and held in situ with surgical tape for $24 \mathrm{~h}$. Similarly, dissolving MN containing OVA were applied manually to a clean, dry, hair-free area on the dorsal skin of the mice. Surgical tape was wrapped around the animal's abdomen to ensure the MN remained in situ for $24 \mathrm{~h}$. All MN arrays were left in situ for $24 \mathrm{~h}$, after which time they were removed. This process was repeated at day 0,28 , and 56, namely prime, boost, and second-boost respectively.

\subsection{Extraction of serum}

Mice were individually placed in a heat box set at $38^{\circ} \mathrm{C}$ for a maximum of 5 min to facilitate tail vein dilation for blood sampling. Mice were restrained and tails were pierced with a Terumo $^{\circledR} 25 \mathrm{G}$ hypodermic needle at the tail base. Twenty microliters of blood samples were collected in non-heparinised Sarstedt Microvette ${ }^{\circledR}$ serum collection tubes. Whole blood samples were incubated at $37^{\circ} \mathrm{C}$ for $60 \mathrm{~min}$, and centrifuged at $2000 \mathrm{rpm}$ for $15 \mathrm{~min}$ in an Eppendorf ${ }^{\circledR}$ rotary refrigerated centrifuge set to $4^{\circ} \mathrm{C}$. The supernatant fluid (serum) was then extracted and aliquoted into $1.5 \mathrm{ml}$ Eppendorf ${ }^{\circledR}$ tubes and stored at $-80^{\circ} \mathrm{C}$ until analysis.

\subsection{Anti-OVA IgG specific ELISA}

Serum samples from immunised mice were analysed for OVA-specific IgG using a commercially available ELISA kit (Alpha Diagnostic International, USA). ELISA analysis was carried out according to the manufacturer's instructions and antibody titres determined by calibrated spectroscopy (Powerwave XS, Bio-Tek Instruments Inc.) at $450 \mathrm{~nm}$ wavelength.

\subsection{Statistical analysis}

Statistical analysis was carried out using Microsoft (Mac Excel $\left.{ }^{\circledR} 2016\right)$ and GraphPad PRISM ${ }^{\circledR}$. The mean \pm standard deviation was calculated and calibration plots generated. Least squares linear regression and analysis of residuals was also carried out. Mann-Whitney U, ANOVA (Sidak correction) and t test's $(p<0.05)$ were used, as appropriate, to define statistical significance. 


\section{Results}

\subsection{Formulation and fabrication of hydrogel-forming and dissolving MNs}

Several polymers have been investigated for fabrication of dissolving MNs, including polyvinylpyrrolidone (PVP), polyvinyl alcohol (PVA) and hyaluronic acid. We have previously reported the successful formulation of dissolving MNs for vaccination purposes using Gantrez ${ }^{\circledR}$ based polymers and as such, this polymer was selected for the experiments conducted herein $[10,11]$. MNs were prepared as described, containing OVA as a model protein antigen. After MNs were removed from the moulds, they were imaged using light microscopy to confirm complete needle formation prior to further experimentation. Figure $2 \mathrm{~A}$ shows representative light microscope images of dissolving MNs fabricated from Gantrez ${ }^{\circledR}$ S97. As shown, the MNs had fully formed, regardless of the OVA constituent. MNs could be consistently produced, using methods applicable to upscale manufacture of dissolving MNs. The measured dimensions of the MNs were approximately $550 \mu \mathrm{m}$ in height, with a base at width of approximately $300 \mu \mathrm{m}$. Importantly, no cracks were evident in the baseplates or the needles of the MN array upon removal of the moulds and MNs could be easily moved intact.

Hydrogel-forming MNs were fabricated from formulations previously reported by our group to consistently and reliably produce MNs [12]. Representative images of such MNs are shown in Figure 2B. Consistent with the dissolving MNs, the hydrogel-forming MNs were removed from the moulds intact and fully formed needles could be visualised by light microscopy. In both cases, the arrays used within this study consisted of a $0.5 \mathrm{~cm}^{2}$ array with 19 x19 needles, much smaller than that of the conventional hypodermic needle (Figure 2E). Upon immersion in PBS, the hydrogel-forming MNs began to swell to a size of approximately $1708 \%$ of their original dry mass, as shown in Figure 2F.

Lyophilised reservoirs containing $2.5 \mathrm{mg}$ OVA were also fabricated through a previously optimised lyophilisation process [Representative photographic images of the reservoirs are shown in Figure $\mathbf{2 C}$, with a light micrograph image of the internal porous structure shown in Figure 2D. The reservoirs were fully formed, removed from their moulds intact, and were robust enough to allow manual handling throughout in vitro and in vivo experiments. 

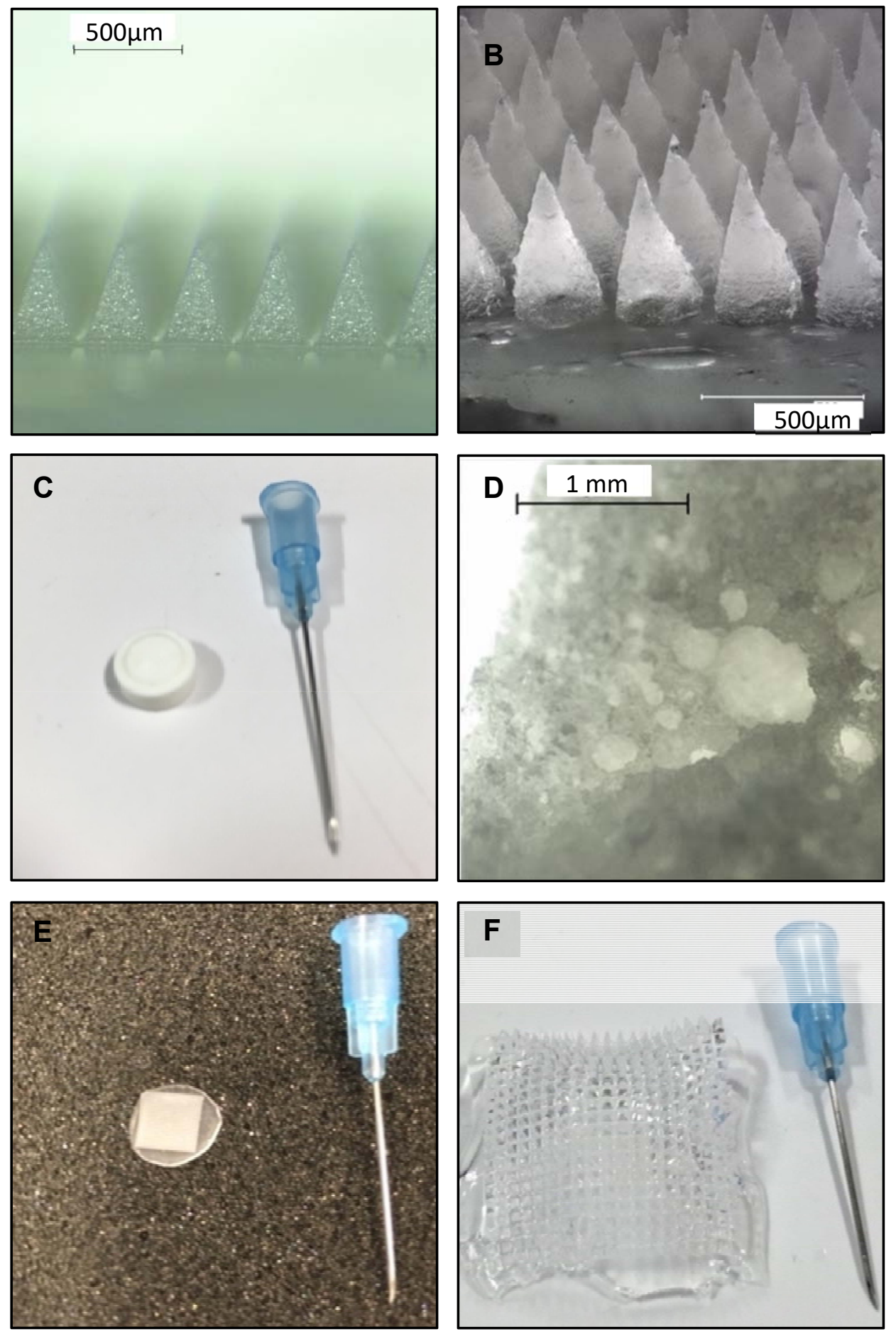

Figure 2. Representative images of MNs arrays and associated lyophilized reservoirs. (A) Digital image of dissolving MN and (B) a hydrogel-forming MN array in the dry state. (C) Digital image of a lyophilised OVA containing reservoir beside a conventional $23 \mathrm{G}$ needle. (D) Light microscope depth-composition image of a hydrogel-forming MN array in the dry state. (E) photograph of a hydrogel-forming MN beside a conventional $23 \mathrm{G}$ needle and (F) A swollen hydrogel-forming MN array beside a conventional 23G needle. 
3.2 Mechanical characterisation and insertion studies of hydrogel-forming and dissolving MNs

For successful vaccination, MNs possess sufficient mechanical properties to successfully and reliably bypass the stratum corneum barrier. Accordingly, experiments were conducted to test the mechanical properties of both $\mathrm{MN}$ platforms using methods previously reported for analysing such parameters [8]. Compression tests using the Texture Analyser were conducted to assess the effects of application of an axial load on the heights of individual needles on both $\mathrm{MN}$ array types. Figure 3A shows the heights of MNs pre- and post-application using manual insertion pressure. As previously stated, the height of the needles on the array post fabrication was $497 \pm 0.9 \mu \mathrm{m}$ for the dissolving MNs and $543 \pm 5.3 \mu \mathrm{m}$ for the hydrogel-forming MNs. The application of manual pressure resulted in a reduction in MN height, from $497 \pm 0.9 \mu \mathrm{m}$ to $491 \pm 3.2 \mu \mathrm{m}$ for the dissolving $\mathrm{MN}$ and $543.8 \pm 5.3 \mu \mathrm{m}$ to $538 \pm 3.2 \mu \mathrm{m}$ for the hydrogelforming MNs respectively. This resulted in a percentage reduction in MN height of approximately 6.04\% (dissolving $\mathrm{MN}$ ) and 5.68\% (hydrogel-forming $\mathrm{MN}$ ). These results are consistent with our previous work with other MN designs [11,13]. Importantly, the MNs did not shatter during compression, nor did the needles appear to bend when examined microscopically.

The insertion properties of both MN types were also investigated to ensure MNs could consistently penetrate the validated skin model, Parafilm $\mathrm{M}^{\circledR}$ and thus, be used for successful vaccination of mice in subsequent experiments. Moreover, for vaccination purposes, it may be important to estimate the depth of $\mathrm{MN}$ insertion, for targeting of skin antigen presenting cells [14]. Figure 3B shows the percentage of holes created in Parafilm $\mathrm{M}^{\circledR}$ layers after insertion of the dissolving and hydrogel-forming MNs. Consistent with the compression results, both MN types demonstrated similar insertion characteristics. As evident, the in vitro insertion testing of the MNs, showed that greater than $80 \%$ of the needles of the array of both MN types inserted to the second Parafilm $\mathrm{M}^{\circledR}$ layer. The average thickness of each Parafilm $\mathbf{M}^{\circledR}$ layer is approximately $126 \mu \mathrm{m}$, and therefore, it could be estimated that the MNs inserted to a depth of at least $250 \mu \mathrm{m}$ equating to previous reports of approximately $50 \%$ of the total needle height [15]. Representative images of the Parafilm $\mathrm{M}^{\circledR}$ layers following insertion of the MNs into the first, second and third layer are displayed in Figure 3C. In short, these results indicate that the MNs fabricated herein, were of sufficient mechanical strength and possessed insertion characteristics to be successfully be used for vaccination purposes. Furthermore, both the dissolving and hydrogel-forming MNs exhibited similar characteristics in terms of mechanical and insertion properties. 
A
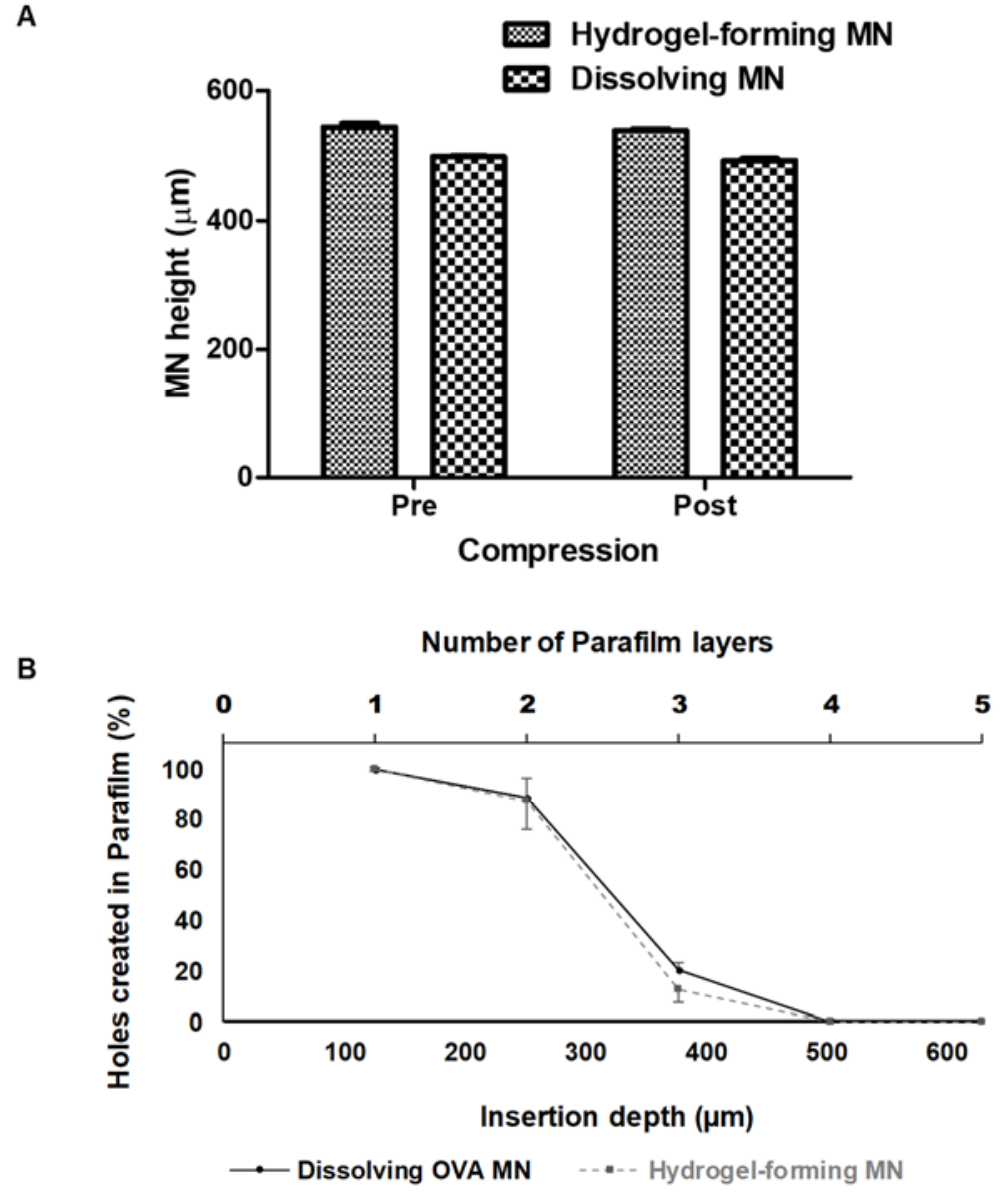

C
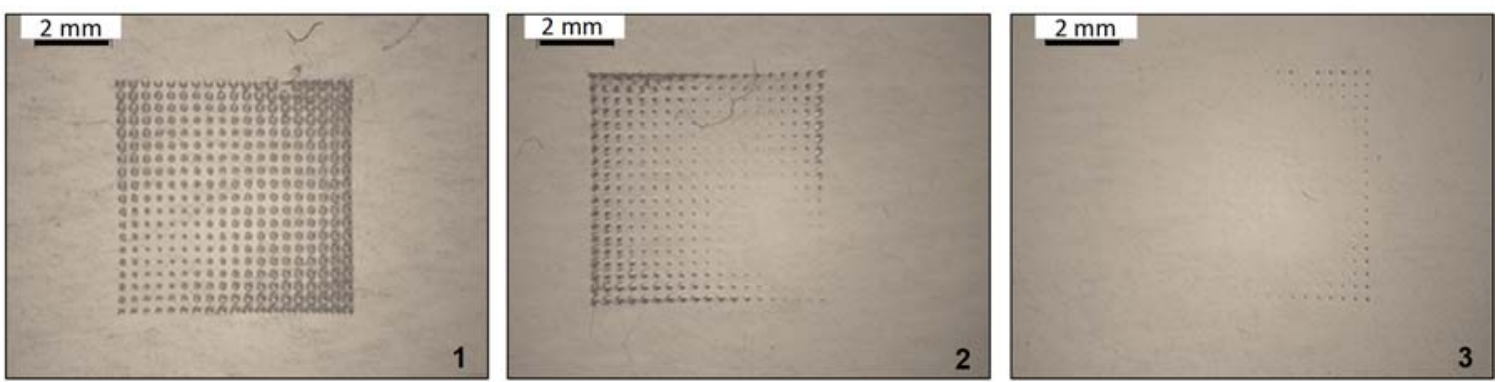

Figure 3. Mechanical characterization of hydrogel-forming and dissolving MNs. (A) Height of MNs pre and post application using manual pressure. (B) Line graph showing the percentage of holes created in Parafilm $\mathrm{M}^{\circledR}$ layers following insertion of dissolving MN containing OVA and hydrogel-forming MN arrays using manual pressure. (C) Representative digital images of (1) Parafilm $\mathrm{M}^{\circledR}$ layer 1, (2) Parafilm $\mathrm{M}^{\circledR}$ layer 2, (3) Parafilm $\mathrm{M}^{\circledR}$ layer, showing the holes created by MNs following insertion. Means \pm SD, $n=5$.

\subsection{In vitro OVA permeation studies}

The dissolving MNs were formulated to contain $2.5 \mathrm{mg}$ of OVA, equivalent to that of what was contained within the reservoir compartment of the hydrogel-forming MN platform. The dissolution profiles of OVA containing reservoirs and dissolving $\mathrm{MN}$ arrays were independently analysed in PBS ( $\mathrm{pH}$ 7.4). The time taken for complete dissolution of the OVA 
containing lyophilised reservoirs and dissolving $\mathrm{MN}$ were $5.23 \pm 0.3 \mathrm{~min}$ and $4.55 \pm 0.7 \mathrm{~min}$, respectively. Furthermore, OVA percentage recovery was assessed by dissolving both the lyophilised reservoirs and dissolving MN in PBS (pH 7.4). Recovery from both lyophilised reservoirs and dissolving $\mathrm{MN}$ arrays was 82.5 and $90.9 \%$, respectively.

Figure 4A shows a schematic representation of the modified Franz cell apparatus used to evaluate OVA permeation in vitro. Dissolving MN arrays containing OVA were weighed postdrying with and without needles, which indicated that the total $\mathrm{MN}$ array mass was $33.1 \pm 2.9$ $\mathrm{mg}$, whereas the $\mathrm{MN}$ with needles removed were $31.2 \pm 3.3 \mathrm{mg}$. As such, the needle component of the MN array was $10.4 \pm 0.4 \%$ of the total $\mathrm{MN}$ array mass. This is an important point to note, as although $2.5 \mathrm{mg}$ of OVA was used to manufacture the dissolving MN array, only 10.4 $\pm 0.4 \%$ of that is available for delivery, assuming only minimal concentrations of OVA is delivered from the baseplate. Figure 4B describes the comparative quantity of OVA used to formulate lyophilised reservoirs and dissolving MN. This graph shows the total OVA (2500 $\mu \mathrm{g}$ ) formulated, the estimated OVA available for delivery from the lyophilised reservoirs and dissolving MN arrays, $100 \%$ and $10.4 \pm 0.4 \%$ of $2500 \mu \mathrm{g}$ respectively, and the quantity of OVA delivered in vitro after $24 \mathrm{~h}$.

Both hydrogel-forming and dissolving MN arrays successfully penetrated neonatal porcine skin, as demonstrated by the OCT images in Figure 4C. An image of the dissolving MN post application in neonatal porcine skin after 60 mins is also shown in Figure 4C and from this, complete dissolution of the needles can be observed. The $24 \mathrm{~h}$ permeation profiles for hydrogel-forming MN arrays with accompanying lyophilised OVA containing reservoirs and dissolving MN arrays were compared (Figure 4D). The mean hydrogel-forming MN-mediated permeation of OVA from lyophilised reservoirs was $674.5 \pm 227.9 \mu \mathrm{g}$ at $24 \mathrm{~h}$, equivalent to $27.0 \pm 9.1 \%$ of the available OVA $(2500 \mu \mathrm{g})$. The mean OVA permeation from dissolving MN arrays peaked at $300 \mathrm{~min}$ at $197.8 \pm 44.6$, equivalent to $7.9 \pm 1.8 \%$ of the total formulated OVA $(2500 \mu \mathrm{g})$, significantly lower than that achieved with the hydrogel-forming $\mathrm{MN}(\mathrm{p}=0.0286)$. However, as stated previously, only $10.4 \pm 0.4 \%$ of the total OVA is contained within the needle tips, representing only $260 \pm 10 \mu \mathrm{g}$. As such $197.8 \pm 44.6 \mu \mathrm{g}$ at $300 \mathrm{mins}$ represents approximately $76.1 \pm 17.2 \%$ of the $260 \pm 10 \mu \mathrm{g}$ OVA contained within the needles. 
A
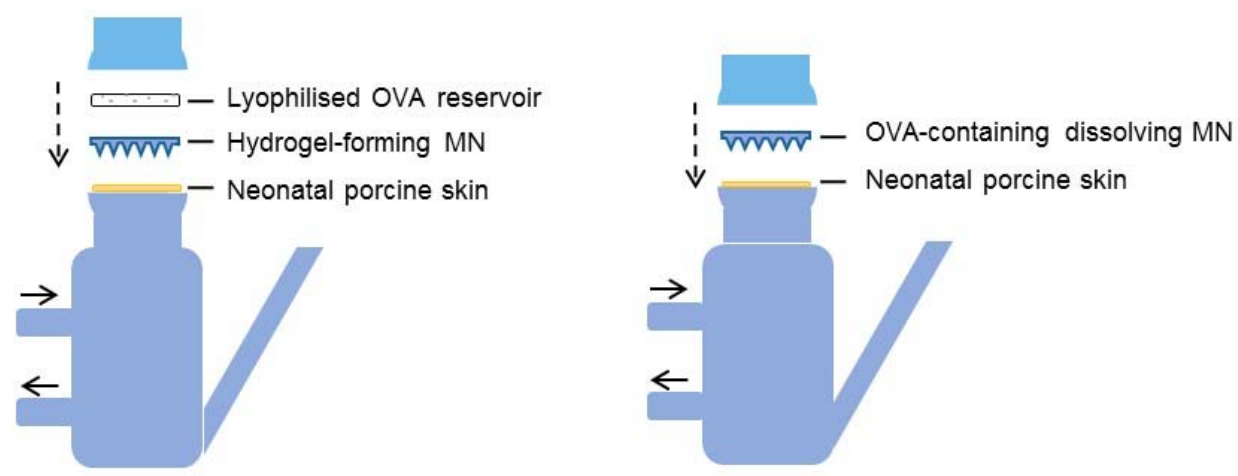

B
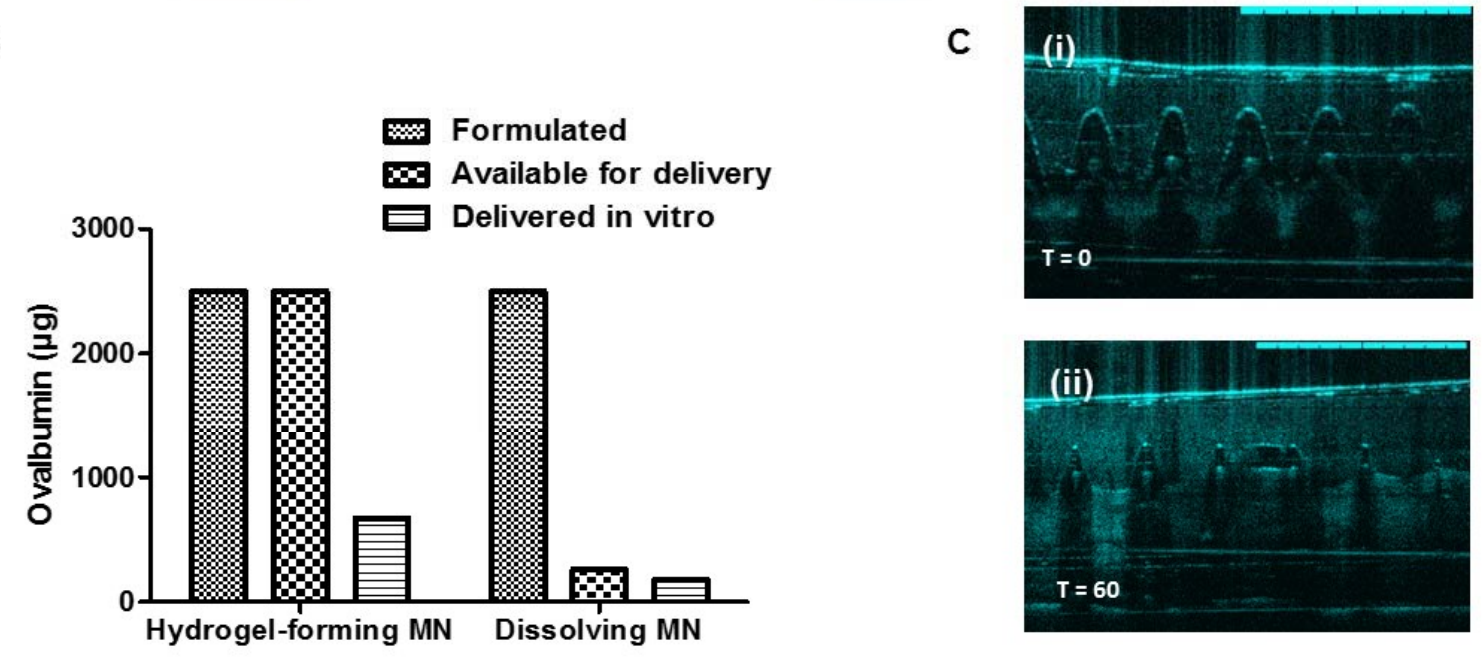

D

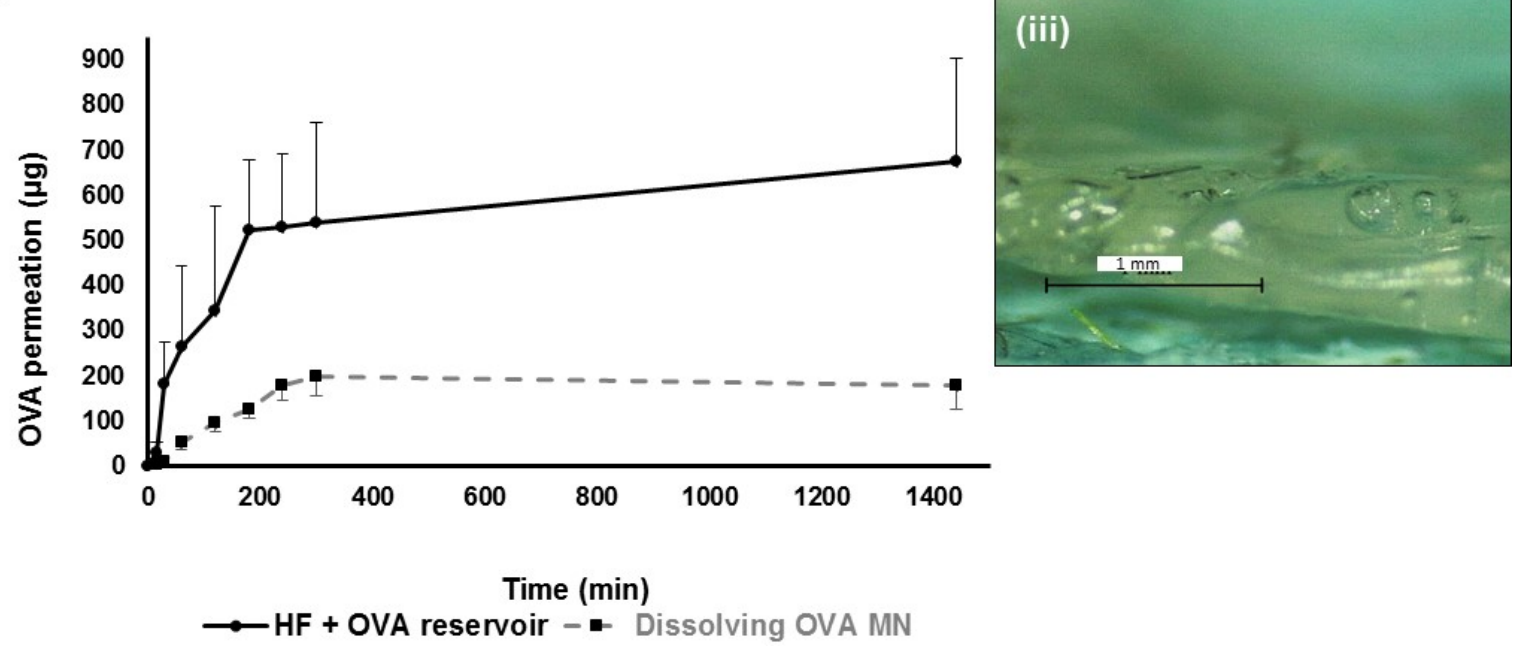

Figure 4. (A) Schematic representation of the Franz cell apparatus used to model the MN-mediated permeation of OVA across excised neonatal porcine skin of $350 \mu \mathrm{m}$ thickness, showing the setup of OVA delivery using a hydrogel-forming MN in combination with lyophilised OVA-containing reservoir and dissolving MN. (B) Bar chart showing the OVA content contained within the hydrogel-forming and dissolving $\mathrm{MN}$ and the cove content delivered across neonatal porcine skin post $24 \mathrm{~h}$ application. (C) In skin visualisation of MNs in neonatal porcine skin using optical coherence tomography. Representative OCT images of dissolving MNs insertion in skin at (i) time 0 (TO) and (ii) post $60 \mathrm{~min}$ (T60) in skin, showing complete $\mathrm{MN}$ dissolution, scale bar $=1 \mathrm{~mm}$. A representative light microscope image of MNs after $60 \mathrm{~min}$ insertion in skin is shown in (iii). (D) Line graph showing OVA permeation across excised neonatal porcine skin over $24 \mathrm{~h}$, using hydrogel-forming MN arrays with OVA loaded lyophilized wafers (HF + OVA reservoir) (2500 $\mu \mathrm{g}$ OVA) and dissolving MN arrays containing OVA (Dissolving OVA MN) $(2500 \mu \mathrm{g})$. Means \pm S.D, $\mathrm{n}=4$. 


\subsection{In vivo vaccination studies using hydrogel-forming and dissolving MNs}

Dissolving and hydrogel-forming MN platforms were applied to the dorsal skin of BALB/c mice using manual pressure for $3 \mathrm{~min}$ and were held in situ with a foam border and surgical tape. Each mouse received either two OVA dissolving MN arrays or two hydrogel-forming $\mathrm{MN}$ arrays with accompanying OVA lyophilised reservoirs. Post-MN application, no showed signs of adverse skin reactions or other adverse effects throughout the prime, boost $\&$ second boost applications.

Mice vaccinated with dissolving OVA MN arrays showed a progressive increase in anti-OVA specific IgG titre over the 70-day sampling period. Of the 8 mice treated with dissolving OVA $\mathrm{MN}$ arrays, the mean anti-OVA specific $\mathrm{IgG}$ titre was $1.75 \times 10^{7} \pm 6.92 \times 10^{6} \mathrm{U} / \mathrm{ml}$ at day 70 , with the highest and lowest anti-OVA specific IgG titres $2.67 \times 10^{7}$ and $3.75 \times 10^{6} \mathrm{U} / \mathrm{ml}$ respectively.

The mice vaccinated using the hydrogel-forming MN and lyophilised OVA reservoirs showed progressive increases in anti-OVA specific IgG titre over the 70-day sampling period. However, this was to a lesser extent than that seen with the dissolving MN cohort. Of the 8 mice treated with hydrogel-forming $\mathrm{MN}$ and lyophilised OVA reservoirs, the mean anti-OVA specific IgG titre was $1.18 \times 10^{6} \pm 1.74 \times 10^{6} \mathrm{U} / \mathrm{ml}$ at day 70 , with the highest and lowest antiOVA specific IgG titres of $5.40 \times 10^{6}$ and $1.40 \times 10^{5} \mathrm{U} / \mathrm{ml}$, respectively. These values were significantly lower than anti-OVA specific IgG titres produced by dissolving OVA MN $(p<0.0001)$, (Figure 5B). 
A

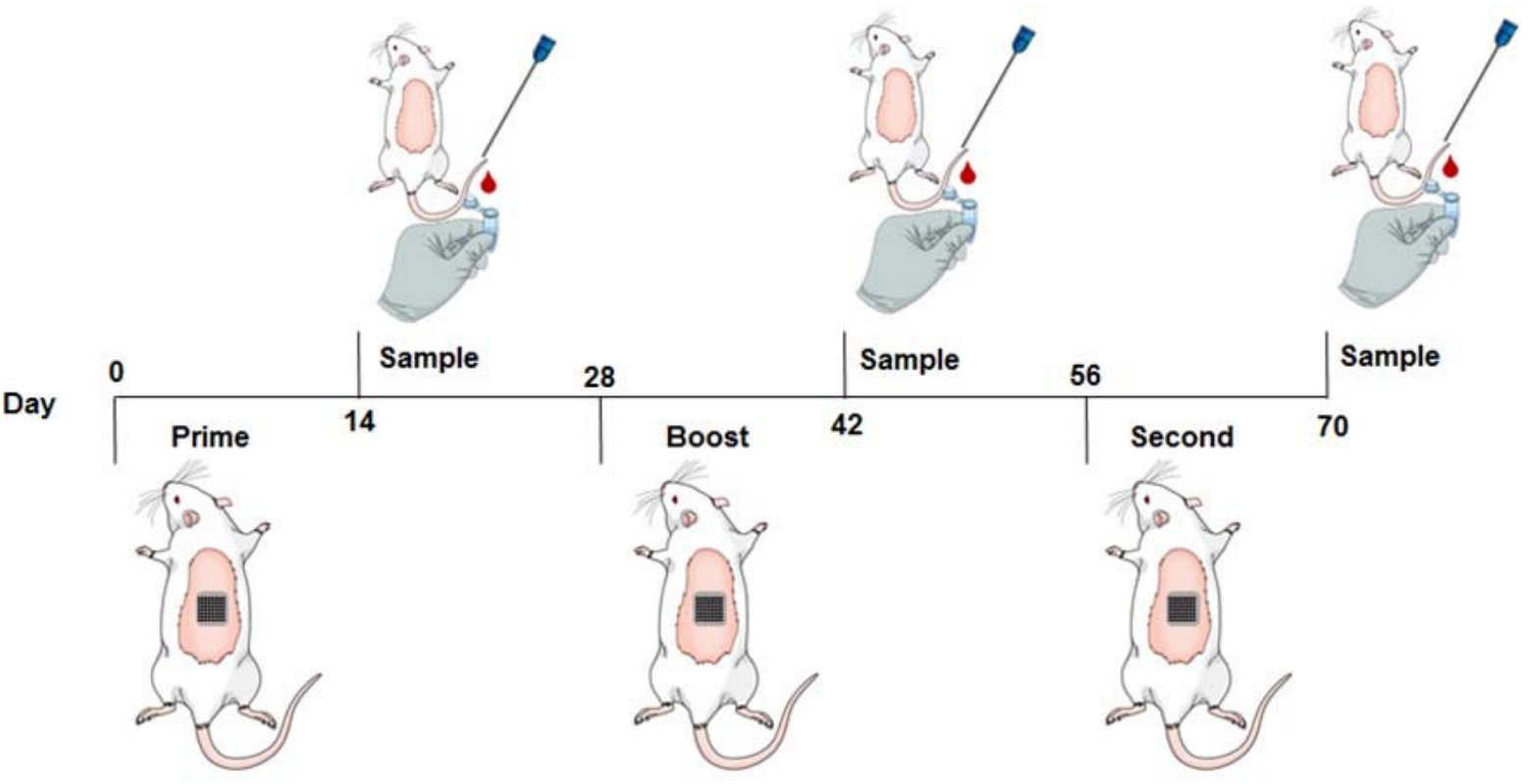

B

$\square$ Hydrogel-forming MN

Dissolving MN

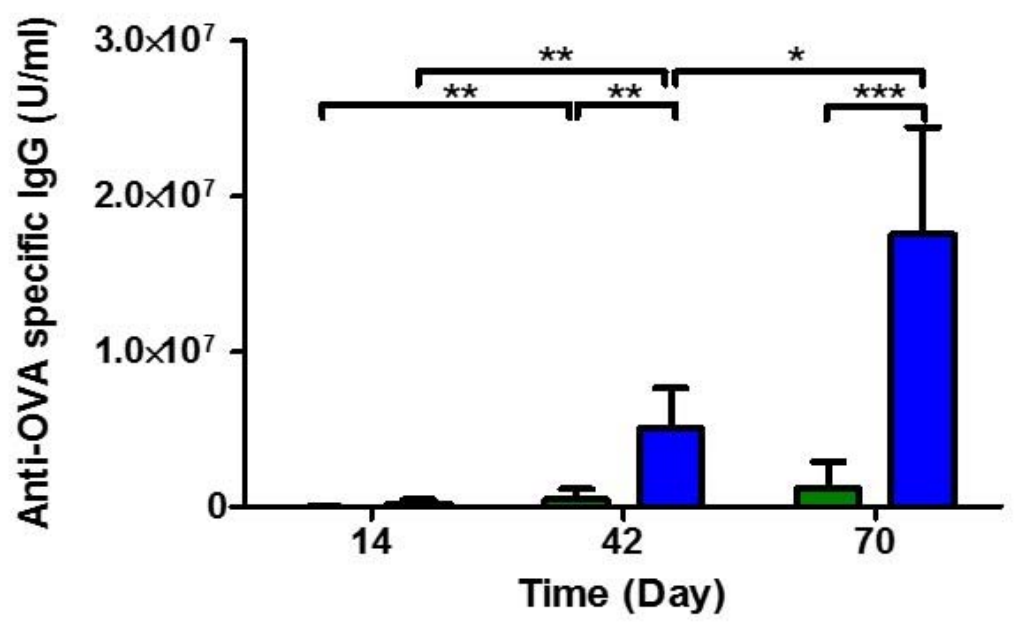

Figure 5. (A) A schematic representation of the vaccination regime and experimental setup. (B) Scatter plots indicating anti-OVA specific IgG in BALB/c mice post prime, boost \& second boost treatments, sampled at 14 , 42 and 70 days for mice which had OVA delivered via hydrogel-forming and dissolving MNs. Means \pm S.D, $\mathrm{n}=$ 8 . 


\section{Discussion}

MN technology has provided a platform for skin vaccination which has the potential to achieve effective immunisation whilst removing many of the risks and drawbacks associated with traditional hypodermic injection. As a result, polymeric MNs have become popular within the academic community; however, their success has been hampered by a lack of evidence to answer current regulatory concerns, such as the effect of polymers deposition and clearance from the body, and the influence of immune response to vaccine antigens. This study has employed industrially scalable manufacturing techniques to fabricate novel hydrogel-forming and dissolving $\mathrm{MN}$ platforms allowing, for the first time, a comparison of the two vaccination systems.

$\mathrm{MN}$ vaccination studies to date have shown that, following $\mathrm{MN}$ insertion, dissolution and subsequent antigen delivery, specific antibody production and the induction of robust cellular responses can be achieved [16]. However, as MN vaccination platforms progress towards commercialisation, transfer of laboratory manufacturing processes to industrial settings may prove challenging. Pertinently for dissolving $\mathrm{MN}$ delivery systems, it is important that biocompatible polymers, which are safe for human use, are employed. Uniformity of chain homogeneity, high levels of quality, and minimal batch-to-batch variation makes the use of synthetic polymers highly attractive to industrial processing. Our previous vaccination studies utilising poly(methylvinylether-co-maleic acid) as polymer base have focused on Gantrez ${ }^{\mathbb{R}}$ AN-139 [10]. However, this polymer is not certified as benzene free [17]. Accordingly, more recent studies have availed of Gantrez ${ }^{\circledR}$ S-97, also a poly(methylvinylether-co-maleic acid) polymer, and as such, this polymer was used to fabricate robust $\mathrm{MN}$ for the experiments conducted herein [11]. It is well known that a number of Gantrez ${ }^{\circledR}$ products have been shown to produce adjuvant effects $[18,19]$. While such adjuvant effects may prove beneficial in terms of vaccination, such polymers have not been used for intradermal vaccination to date, and as such, this may raise some concerns from regulatory bodies as dissolving MNs move towards commercialisation. Although hydrogel-forming MN arrays have been used to deliver a number of compounds transdermally, to date, vaccination strategies have not been tested with this system.

Formulation of materials containing protein antigens can often result in loss of protein structure and antigenicity. The relatively high recovery of OVA from lyophilised reservoirs and dissolving MNs indicate that the manufacturing methods employed in this study are highly 
conservative. Here, the needle tips comprise $10.4 \pm 0.4 \%$ of the $\mathrm{MN}$ array by mass. This aspect of dissolving $\mathrm{MN}$ has potential cost challenges due to vaccine wastage. A number of studies have therefore addressed such issues through developing alternative methods of manufacture referred to as two-step MNs. However, two step manufacturing methods have been described in order to overcome this particular issue [20]. OVA recovery from lyophilised reservoirs indicated that minimal loss of OVA was observed during the formulation process. Lyophilisation is a commonly used formulation technique for protein vaccine agents and can provide a stable environment, avoiding many destabilization events present in other formulation processes and can, in some cases, circumvent the need for cold chain storage [21].

The MN insertion studies confirm that both dissolving and hydrogel-forming MN successfully inserted into Parafilm $\mathrm{M}^{\circledR}$ in vitro. Considering the $\mathrm{MN}$ arrays have heights of $550 \mu \mathrm{m}$, this indicates that the MN tips are inserting up to $69 \%$ of their height. The permeation of OVA from hydrogel-forming MN systems represent $27.0 \pm 9.1 \%$ of the available OVA from the lyophilised reservoirs. From the in vitro data presented in Figure 4D, it is evident that, as the hydrogel-forming MN swells, within the first $15 \mathrm{~min}$, there is minimal delivery of OVA. Similarly, as the lyophilised reservoir dissolves, OVA concentration rises to a plateau at 180 min. The concentration of OVA rises only marginally between this time point and the final sample at $24 \mathrm{~h}$. This suggests that the maximum OVA permeation is largely complete within this initial timeframe. Permeation of OVA from the dissolving $\mathrm{MN}$ is lower than that observed from the hydrogel-forming MN platform. OVA permeation from dissolving $\mathrm{MN}$ represents only $7.9 \pm 1.8 \%$ of the total OVA available in the MN array. However, this is not surprising when viewed in respect to the proportion of the MN array by weight comprising of needles is only $10.4 \pm 0.4 \%$. With almost $90 \%$ of the $\mathrm{MN}$ array comprising the baseplate, this significantly reduces the expected OVA permeation. Low levels of permeation of OVA indicate that, only OVA confined to the needle tips themselves is available for permeation, with minimal delivery OVA from the supporting baseplate. This is concurrent with previous reported studies using dissolving MNs for protein delivery [12].

Vaccination following a traditional prime, boost \& second boost schedule was implemented in order to generate OVA-specific antibodies and provide long-term vaccine efficacy [22]. The results show significant incremental increases in anti-OVA specific IgG serum titres. The mice treated with the combined hydrogel-forming MN/ OVA-containing lyophilised reservoirs also showed incremental increases in anti-OVA specific IgG serum titres. This data supports the 
current theory that, as the hydrogel-forming MN array swells and absorbs interstitial fluid, the lyophilised reservoirs dissolves releasing OVA. The OVA is then free to permeate through the $\mathrm{MN}$ array and into the skin, for induction of subsequent immune responses [23].

Mice vaccinated with dissolving MN showed significantly high OVA specific IgG responses, in comparison to that of mice vaccinated with the hydrogel-forming $\mathrm{MN}$ and accompanying reservoirs. Such results are surprising considering the fact that such dissolving platforms delivered significantly less OVA There are a number of contributing factors which may be responsible for such effects. Firstly, dissolving MN systems operate through a different mechanism of antigen delivery, depositing antigen into skin layers at a much faster rate than that of hydrogel-forming MNs. As such, the kinetics of antigen delivery may be a contributing factor to the response seen in the experiments conducted herein. To date, there have been no studies investigating the influence of antigen release from polymeric MNs and their subsequent induction of immune response. Only hollow MN arrays, studied by Schipper et al. in 2016 have demonstrated that intradermal delivery of antigens over a longer period of time can result in higher antibody titres with further studies warranted to address such issues in polymeric MN systems [24].

Gantrez $^{\circledR}$ S-97 has a low $\mathrm{pH}(\mathrm{pH}$ 2) in solution and so it is possible that it may facilitate enhanced cell migration to the site of $\mathrm{MN}$ application in skin and therefore, result in an increased immune response. Vermeulen and co-workers reported that an acidic environment improved antigen uptake by dendritic cells [25]. Martinez et al. also reported that exposure (90-180 min) of dendritic cells to $\mathrm{pH}$ 6.5, resulted in dendritic cell maturation [26]. However, longer dendritic cell exposure to this $\mathrm{pH}$ resulted in the inability of dendritic cells to progress to a mature phenotype. While these studies demonstrated enhanced uptake and maturation of dendritic cells, the $\mathrm{pH}$ used was approximately $\mathrm{pH}$ 6. Following $\mathrm{MN}$ application, a more extreme acidic environment is created within the mouse skin which may have systemic effects. Hydrogel-forming MN arrays, however, absorb interstitial fluid and acquire a more neutral $\mathrm{pH}$, which in contrast may not provoke as extensive cell migration resulting in a lower immune response, despite the significantly higher levels of OVA delivered using the hydrogel system.

Another possible explanation for the enhanced responses observed with dissolving $\mathrm{MN}$ is that the potential adjuvant effects are conferred by polymer-OVA interactions. The hydrogelforming MN array platform is likely to result in OVA delivered into the skin as a free antigen 
with only minimal movement of polymeric material into the skin, as the hydrogel-forming $\mathrm{MN}$ arrays are removed fully intact. In contrast, as the polymeric chains of dissolving $\mathrm{MN}$ arrays dissolve into interstitial skin fluid, it is anticipated that entangled OVA-polymer particles may be released. As these OVA-polymer particles are released into the skin, antigen uptake and processing will undoubtedly be influenced by the polymer constituents. Polymeric adjuvants are widely used, with examples of polymeric nanoparticles used to enhance immune modulation [27]. Similar biocompatible polymers, such as poly(lactide), have been used for their adjuvant effect [28]. Manufacture of polymeric dissolving MN arrays should therefore be considered with this in mind.

Any potential adjuvant effects of polymeric material deposited in the skin could enhance immune responses in a positive manner. However, upon repeated exposure, the increased immune response may be detrimental and prove unacceptable for repeated administration. The exact cause of the adjuvant effect seen in this study is yet to be elucidated. The deposition of an acidic polymer such as Gantrez ${ }^{\circledR}$ S-97, or similarly, the large molecular weight may hold the explanations behind these effects. Previously, by McCrudden et al. highlighted the efficacy of dissolving MN arrays manufactured from Gantrez ${ }^{\circledR}$ AN-139 [12]. In this study, dissolving OVA MN also showed significantly higher anti-OVA specific IgG antibody titres than intradermal control, supporting trends observed in the current work. Although the longevity of antibody titre ( $>70$ days) was not measured in this study, there may be potential for antigen dose saving opportunities with dissolving MN arrays fabricated from Gantrez ${ }^{\circledR}$ S-97. 


\section{Conclusion}

Both dissolving \& hydrogel-forming MN array systems have been successfully manufactured using industry scalable methods, providing robust MNs that can be inserted and handled. In the first direct comparison of the vaccination potential for these systems, dissolving MNs offered enhanced immune responses in comparison to that of hydrogel-forming MNs for OVA vaccination in mice. This work highlights the need to examine further the links between polymer chemistry, chain length, and the degree of polymer interaction with vaccine agents in order to develop an understanding of the potential adjuvant effects conferred by such delivery platforms. In this study, dissolving $\mathrm{MN}$ arrays have yielded enhanced immune responses, suggesting the possibility lower dosing and equivalent outcomes as traditional needle and syringe methods. However, further studies are warranted to elucidate the precise mechanisms of such effects taking the abovementioned factors into consideration. 


\section{References}

1. World Health Organisation, 2017. World Health Organization - Immunization coverage. WHO factsheet.

2. Larraneta, E., Lutton, R.E.M., Woolfson, D., and Donnelly, R.F. 2016. Microneedle arrays as transdermal and intradermal drug delivery systems: Materials science, manufacture and commercial development. Materials Science and Engineering R: Reports, 104, pp.1-32.

3. Al-Zahrani, S., Zaric, M., McCrudden, C., Scott, C., Kissenpfennig, A., and Donnelly, R.F. 2012. Microneedle-mediated vaccine delivery: harnessing cutaneous immunobiology to improve efficacy. Expert Opinion on Drug Delivery, 9(5), pp.541-50.

4. Kim, Y.-C., and Prausnitz, M.R. 2012. Enabling skin vaccination using new delivery technologies. Current topics in microbiology and immunology, 351(1), pp.77-112.

5. Donnelly, R.F., Singh, T.R.R., Garland, M.J., Migalska, K., Majithiya, R., McCrudden, C.M., Kole, P.L., Mahmood, T.M.T., McCarthy, H.O., and Woolfson, A.D. 2012. Hydrogel-Forming microneedle arrays for enhanced transdermal drug delivery. Advanced functional materials, 22(23), pp.4879-4890.

6. Donnelly, R.F., McCrudden, T.T.C., Alkilani, A.Z., Larraneta, E., McAlister, E., Courtenay, A.J., Kearney, M.C., Singh, T.R.R., McCarthy, H.O., Kett, V.L., CaffarelSalvador, E., Al-Zahrani, S., and Woolfson, A.D. 2014. Hydrogel-forming microneedles prepared from 'super swelling' polymers combined with lyophilised wafers for transdermal drug delivery. PloS one, 9(10), p.e111547.

7. McCrudden, M.T.C., Alkilani, A.Z., Courtenay, A.J., McCrudden, C.M., McCloskey, B., Walker, C., Alshraiedeh, N., Lutton, R.E., Gilmore, B.F., Woolfson, A.D., and Donnelly, R.F. 2015. Considerations in the sterile manufacture of polymeric microneedle arrays. Drug delivery and translational research, 5(1), pp.3-14.

8. Larrañeta, E., Moore, J., Vicente0Perez, E.M., Gonzalez-Vazquez, P., Lutton, R.E., Woolfson, A.D., and Donnelly, R.F. 2014. A proposed model membrane and test method for microneedle insertion studies. International Journal of Pharmaceutics, 472(1-2), pp.65-73.

9. Migalska, K., Morrow, D., Garland, M.J., Thakur, R., Woolfson, A.D., and Donnelly, R.F. 2011. Laser-engineered dissolving microneedle arrays for transdermal macromolecular drug delivery. Pharmaceutical Research, 28(8), pp.1919-30.

10. McCrudden, M.T.C., Alkilani, A.Z., Mccrudden, C.M., McAlister, E., McCarthy, H.O., Woolfson, A.D., and Donnelly, R.F. 2014. Design and physicochemical characterisation 
of novel dissolving polymeric microneedle arrays for transdermal delivery of high dose, low molecular weight drugs. Journal of Controlled Release, 180(1), pp.71-81.

11. Rodgers, A.M., McCrudden, M.T.C., Vicente-Perez, E.M., Dubois, A.V., Ingram, R.J., Larraneta, E., Kissenpfennig, A., and Donnelly, R.F. 2018 Design and characterisation of a dissolving microneedle patch for intradermal vaccination with heat-inactivated bacteria: A proof of concept study. International Journal of Pharmaceutics. 549(1-2) pp. 87-95

12. McCrudden, M.T.C., Torrisi, B.M., Al-Zahrani, S., McCrudden, C.M., Zaric, M., Scott, C.J., Kissenpfennig, A., McCarthy, H.O., and Donnelly, R.F. 2014. Laser-engineered dissolving microneedle arrays for protein delivery: Potential for enhanced intradermal vaccination. Journal of Pharmacy and Pharmacology, pp.409-425.

13. Gozalez-Vazquez, P., Larraneta, E., McCrudden, M.T.C., Jarrahian, C., Rein-Weston, A., Quintanar-Solares, M., Zehrung, D., McCarthy, H., Courtenay, A.J. and Donnelly, R.F. 2017. Transdermal delivery of gentamicin using dissolving microneelde arrays for potential treatment of neonatal sepsis. Journal of Controlled Release, 265, pp 30-40.

14. Zaric, M., Lyubomska, O., Touzelet, O., Poux, C., Al-Zahrani, S., Wallace, L., Terhorst, D., Malissen, B., Henri, S., Power., U.F., Scott, C.J., Donnelly, R.F., Kissenpfennig, A. 2013. Skin dendritic cell targeting via microneedle arrays laden with antigenencapsulated poly-D,L-lactide-co-glycolide nanoparticles induces efficient antitumor and antiviral immune responses. ACS nano. 7(3) pp 2042-55.

15. Quinn, H.L., Bonham, L., Hughes, C.M., and Donnelly, R.F. 2015 Design of a dissolving microneedle platform for transdermal delivery of a fixed-dose combination of cardiovascular drugs. Journal of Pharmaceutical Science. 104(10), pp 3490-500.

16. Rouphael, N.G., Paine, M., Mosley, R., Henry, S., McAllister, D.V., Kalluri, H., Pewin, W., Frew, P.M., Yu, T., Thornburg, N.J., Kabbani, S., Lai, L., Vassilieva, E.V., Skountzou, I., Compans, R.W., Mulligan, M.J., Prausnitz, M.R., and TIV-MNP 2015 Study Group. 2017. The safety, immunogenicity, and acceptability of inactivated influenza vaccine delivered by microneedle patch (TIV-MNP 2015): A randomised, partly blinded, placebo-controlled, phase 1 trial. The Lancet, 6736(17), pp.1-10.

17. Ashland website. Gantrez AN 139. Available: http://www.ashland.com/products. [Accessed August 29, 2017].

18. Vandamme, K., Melkebeek, V., Cox, E., Remon, J.P., and Vervaet, C. 2011. Adjuvant effect of Gantrez AN nanoparticles during oral vaccination of puglets against F4+enterotoxigneic Escherichia coli. Veterinary Immunology and Immunopathology. 
139, pp.148-155.

19. Tamayo, I., Irache, M., Mansilla, C., Ochoa-Reparaz, J., Lasarte, J., and Gamazo, C. 2010. Poly(anhydride) Nanoparticles Act as Active Th1 Adjuvants through Toll-Like Receptor Exploitation. Clinical and Vaccine Immunology,17(9), pp.1356-1362.

20. Lutton, R.E.M., Moore, J., Larraneta, E., Ligett, S., Woolfson, A.D., and Donnelly, R.F. 2015. Microneedle characterisation: the need for universal acceptance criteria and GMP specifications when moving towards commercialisation. Drug Delivery and Translational Research, 5(4), pp.313-331.

21. Hansen, L.J.J., Daoussi, R., Vervaet, C., Remon, J.P., and De Beer, T.R.M. 2015. Freezedrying of live virus vaccines: A review. Vaccine, 33(42), pp.5507-5519.

22. Fiorino, F., Pettni, E., Pozzi, G., Medaglini, D., and Ciabattini, A. 2013. Prime-boost strategies in mucosal immunization affect local IgA production and the type of Th response. Frontiers in Immunology, 4(5), pp.1-8.

23. Chomiczewska, D., Trznadel-Budzko, E., Kaczorowska, A., and Rotsztejn, H. 2009. The role of Langerhans cells in the skin immune system. Polski Merkuriusz Lekarski, 26(153), pp.173-177.

24. Schipper, P., van der Maaden, K., Romeijn, S., Oomens, C., Kerten, G., Jiskoot, W., and Bouwstra, J. 2016. Repeated fractional intradermal dosing of an inactivated polio vaccine by a single hollow microneedle leads to superior immune responses. Journal of Controlled Release., 242 pp.141-147.

25. Vermeulen, M., Giordano, M., Trenabi, A.S., Sedlik, C., Gamberale, R., FernandezCalotti, P., Salamone, G., Raiden, S., Sanjurjo, J. and Geffner, J.R. 2004. Acidosis improves uptake of antigens and MHC class I-restricted presentation by dendritic cells. Journal of Immunology, 172(5) pp. 3196-3204

26. Martinez, D., Vermeulen, M., von Euw, E., Sabatte, J., Maggini, J., Ceballos, A., Trevani, A., Nahmod, K., Salamone, G., Barrio, M., Giordano, M., Amigorena, S., and Geffner, J. 2007. Extracellular acidosis triggers the maturation of human dendritic cells and the production of IL-12. Journal of Immunology. 179(3) pp.1950-1959.

27. Trimaille, T. and Verrier, B., 2015. Micelle-Based Adjuvants for Subunit Vaccine Delivery. Vaccines, 3, pp.803-813.

28. Pavot, V., Rochereau, N., Primard, C., Genin, C., Perouzel, E., Lioux, T., Paul, S., and Verrier, B. 2013. Encapsulation of Nod1 and Nod2 receptor ligands into poly(lactic acid) nanoparticles potentiates their immune properties. Journal of Controlled Release, 167(1), pp.60-67. 